\title{
||||||||||||||||||||||||||||||||||||||||||||||||||||||||||||||||||.
}

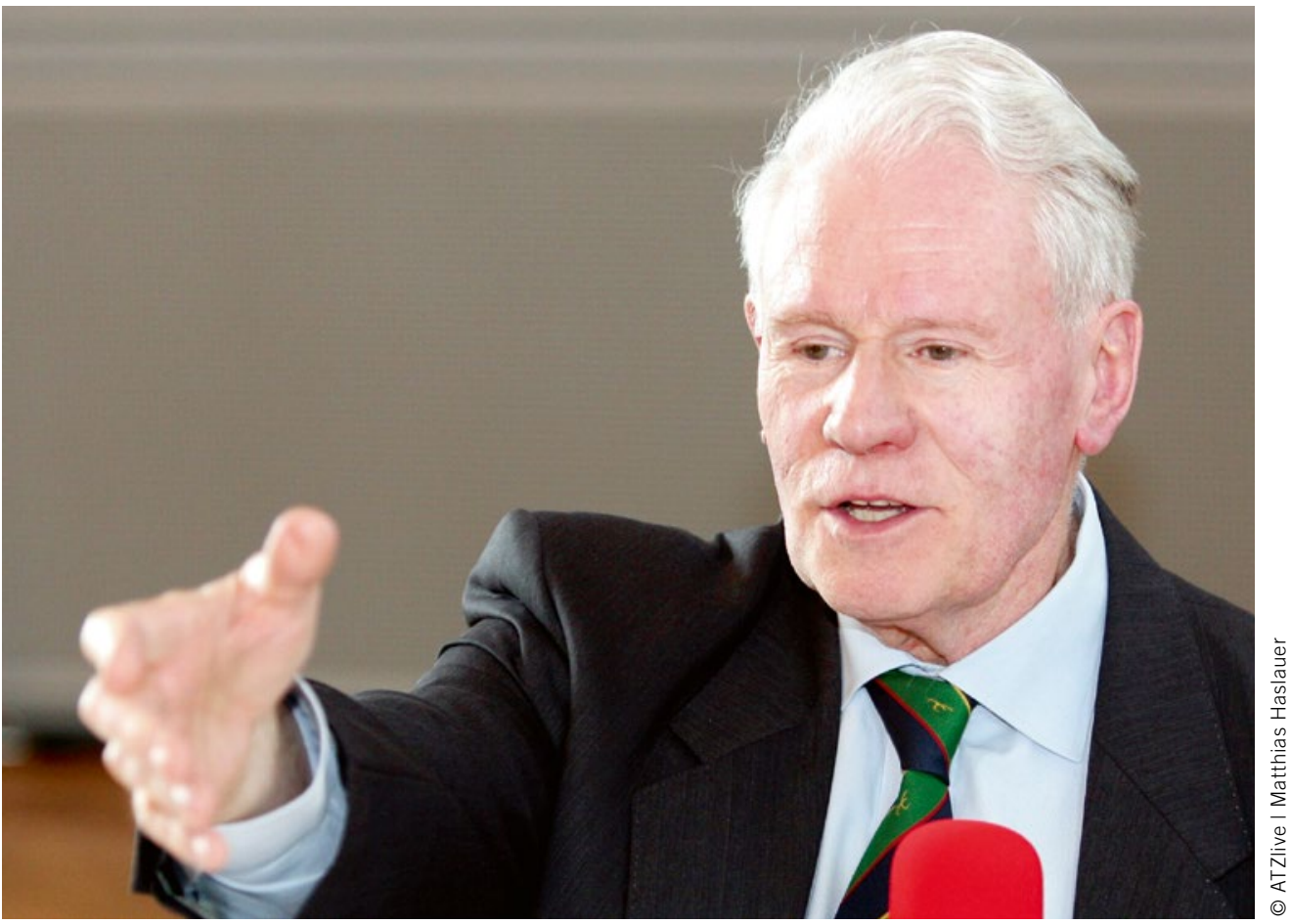

Prof. Dr.-Ing. Dr.-Ing. E. h. Hans-Hermann Braess Mitherausgeber des Handbuchs Kraftfahrzeugtechnik im Springer-Vieweg-Verlag, seit 50 Jahren ATZ-Autor

\section{Komplexität im Automobilbau}

Zielkonflikte und Komplexität - das sind zwei Mega-Herausforderungen der Automobilindustrie. Komplexe Verhältnisse verbindet man zumeist mit der Variantenvielfalt. Ein genauerer Blick zeigt aber, dass man es mit einem größeren Umfang an Dimensionen zu tun hat, die sich in sieben oder mehr Kategorien gliedern lassen. Die Gesamtthematik beginnt bei den zielkonfliktbeladenen Anforderungen: mit immer anspruchsvolleren Kunden, unterschiedlichen Märkten und Gesetzgebern sowie wirtschaftlichen und industriellen Rahmenbedingungen.

Der zweite Bereich umfasst die Technik- und Systemkomplexität: Schon beim Antrieb kommt ein Großteil aller physikalischen, werkstofflichen und energetischen Prinzipien in Frage, wie die Vielfalt möglicher Hybridantriebe zeigt. Andere hochaktuelle Beispiele betreffen Software- und Vernetzungskomplexität oder Elektrochemie. Beim Gesamtfahrzeug sind heute so gut wie alle Technik- und Wissenschaftsbereiche beteiligt.

Baukästen, Plattformen und Modulkonzepte sind Stichworte für die dritte Ebene: die Komponenten- und Variantenkomplexität. Ziel ist, mit einem Minimum an Entwicklungs- und Investitionsaufwendungen ein Maximum an Typenvielfalt darzustellen. Wurde in der Anfangszeit konstruiert, gebaut und auf der Straße erprobt, gibt es heute eine Fülle sich ergänzender und zumeist computergestützter Produktentstehungsmethoden, die von der Findung der Grundkonzepte über die Konstruktion bis zu Qualitätssicherung und Recycling reichen, ergo numero 4.
Die fünfte Kategorie betrifft die heute oftmals weltumspannende Wertschöpfungsketten-Komplexität: Hier geht es sowohl um „Make or buy“ als auch um ausgefeiltes Zusammenwirken von System- und Komponentenlieferanten an allen Produktionsstätten mit den zugehörigen Logistiksystemen.

Genügte früher ein Projektmanagement für die Steuerung der Teilaufgaben, sind heute ganzheitliche Prozessketten erforderlich, also im sechsten Bereich die Sicherung der effektiven und störungsfreien Abfolge aller Teilschritte. Bei der Vielzahl aller Beteiligten mit ihren schon komplexen Teilaufgaben ist dies alles andere als eine triviale Herausforderung. Siebtens benötigen die OEMs heute die Mithilfe spezialisierter Dienstleister. Deren teilweise sich überlappenden Kompetenzen stellen wohl ebenfalls eine Komplexitätsdimension dar.

Die Liste ließe sich noch erweitern, so um Organisations- und Mitarbeiteraspekte: Heute genügen nicht mehr wie früher kreative Konstrukteure, versierte Versuchsingenieure und erfahrene Fertigungspraktiker. Auch weitere methodische Themen wie Wirkkettenanalysen, Ökobilanzen, unternehmensweites Wissensmanagement sowie Mobilitätsfragen sind heute anspruchsvolle Aufgaben. Und über allem steht Zeit- und Kostendruck, wahrlich keine leichte Aufgabe für Industrie und Beschäftigte. Bei allem ist zu beachten, dass extreme gesetzliche Vorgaben nicht zu Lösungen führen, denn sie sind kaum erschwinglich oder finden in sonstiger Hinsicht keine Kundenakzeptanz. 